\title{
Kindness and cellular aging: A pre-registered experiment testing the effects of prosocial behavior on telomere length and well-being
}

\author{
Megan M. Fritz ${ }^{\text {a, }}$, Lisa C. Walsh ${ }^{a}$, Steven W. Cole ${ }^{b}$, Elissa Epel ${ }^{c}$, Sonja Lyubomirsky ${ }^{a}$ \\ ${ }^{a}$ Department of Psychology, University of California, Riverside, Riverside, CA, USA \\ ${ }^{\mathrm{b}}$ Department of Psychiatry, University of California, Los Angeles, Los Angeles, CA, USA \\ ${ }^{\mathrm{c}}$ Department of Psychiatry, University of California, San Francisco, San Francisco, CA, USA
}

\section{A R T I C L E I N F O}

\section{Keywords:}

Well-being

Telomeres

Loneliness

Prosocial behavior

\begin{abstract}
A B S T R A C T
Objective: Prosocial behavior can improve psychological well-being and physical health. However, the underlying biological mechanisms that mediate the relationship between prosociality and health remain unclear. In this preregistered experiment, we tested whether a 4-week kindness intervention could slow leukocyte telomere shortening and increase well-being.

Methods: Community adults $(N=230)$ were randomly assigned to complete 1 of 3 activities, each week for 4 weeks: to perform 3 kind acts for other people, to perform 3 kind acts for themselves, or to list daily activities. At baseline and post-intervention, participants came to the lab to provide a small dried blood spot (DBS) sample via finger prick for analysis of telomere length. Participants completed psychological measures (e.g., loneliness, life satisfaction) at baseline, post-intervention, and at the 2-week follow up.

Results: Participants who performed kind acts for others did not demonstrate hypothesized changes in well-being, nor in telomere length, relative to controls. Exploratory analyses revealed that, relative to controls, participants who did kind acts for others showed reductions in loneliness through the 2-week follow up.

Conclusions: The salubrious effects of prosocial behavior in the short term are not likely due to the inhibition of cellular aging (at least as indexed by telomere length). However, extending kindness to others holds promise as a future research direction for interventions to alleviate loneliness.
\end{abstract}

Kindness is thought to be vital to human survival and well-being. Empirical research indicates that helping or sharing to benefit another person (i.e., prosocial behavior) confers benefits not just for the target (or receiver) of kindness, but also for the actor (or doer). Kindness intervention research has focused primarily on increasing well-being outcomes. Yet, doing acts of kindness may also ameliorate loneliness and stress. Volunteering, a form of prosocial behavior, has been linked with reductions in loneliness (Carr et al., 2018). Doing kind acts for others may thereby promote feelings of closeness that lead one to feel less isolated and lonely. Additionally, providing social support is positively associated with receiving social support (Bowling et al., 2005). Thus, providing help to others may garner help from others, potentially reducing stress (as tasks are completed more easily) and alleviating loneliness (as individuals realize they are cared for and valued).

\section{Prosocial behavior and health}

Prosocial behavior may also benefit physical health (Brown \& Brown, 2015; Eisenberger \& Cole, 2012). In a meta-analysis of five longitudinal cohort studies, Jenkinson et al. (2013) found that volunteers experienced a $22 \%$ reduced mortality risk compared to non-volunteer counterparts. Experimental work directly testing the effects of induced prosocial behavior on biological health has been limited, but the existing work is promising. For example, participants randomly assigned to perform prosocial acts for others over a 4-week period showed significant reductions in proinflammatory gene expression profiles (Nelson-Coffey et al., 2017). Other experimental work suggests that enhanced prosocial behavior (e.g., generativity writing, volunteering) leads to reductions in circulating inflammatory markers and in pro-inflammatory gene expression (Moeini et al., 2020; Schreier et al., 2013). Further, a number of studies have found indirect effects of prosocial behavior on health-related biomarkers, via increases in support-giving (Moeini et al.,

\footnotetext{
* Corresponding author. Department of Psychiatry, University of Pittsburgh, USA.

E-mail address: mfrit001@ucr.edu (M.M. Fritz).
} 
2018) or eudaimonic well-being (Seeman et al., 2020). Taken together, these findings offer preliminary evidence that helping behavior may positively impact human health by modulating health-relevant physiological processes (Brown \& Brown, 2015; Eisenberger \& Cole, 2012).

\subsection{Cellular aging}

One promising area for further research is investigating the relationship between prosocial behavior and the length of telomeres. Telomeres are DNA-protein structures that serve as protective end caps for eukaryotic chromosomes; they function to maintain chromosomal stability across cell replications (Blackburn, 2000; Blackburn et al., 2015). Telomeres progressively shorten with each somatic cell replication; thus, over an individual's lifespan, telomere length normatively shortens (Blackburn et al., 2015). Past work suggests that telomere lengthening is not only possible, but that the overall shortening process may be nonlinear; in other words, telomeres likely shorten over time in an oscillatory manner (Epel, 2012). It is not clear whether these short-term changes are due to natural homeostatic mechanisms or representative of a meaningful response to real changes in health or environment.

Telomeres are responsive to threats and/or damage to the genome, and may serve as "first responders" to protect DNA (Blackburn et al., 2015). Importantly, telomere length is associated with diseases of aging (Codd et al., 2013), and telomere shortening may serve as both a catalyst and a consequence of disease (Blackburn et al., 2015). Leukocyte telomere length (LTL) is a measure of immune cell senescence, a process that may influence the progression of inflammation-related disease such as cardiovascular disease (Blackburn et al., 2015).

\subsection{Telomere interventions}

Some trials have tested whether psychological and/or behavioral interventions may positively influence telomere length. Meditative, lifestyle, and psychosocial interventions have produced reductions in the rate of LTL shortening or increases in activity of telomerase, an enzyme that counteracts telomere shortening (Biegler et al., 2012; Conklin et al., 2018; Jacobs et al., 2011; Ornish et al., 2013; Schutte \& Malouff, 2014). However, results from larger trials have been mixed. One trial found no effects of various types of contemplative training on telomere length over a 3-month period (Puhlmann et al., 2019). In contrast, a randomized trial found that loving-kindness meditation was associated with telomere maintenance, compared to mindfulness training and a control condition, over a roughly 2-month period (Le Nguyen et al., 2019). Although these results are promising, existing studies are subject to several methodological limitations, such as small sample sizes (e.g., ns of 30-40 per experimental condition), widely differing covariates between studies, quasi-experimental designs, self-selected participants, and multicomponent interventions. Also, given that many of these interventions require trained interventionists (e.g., meditation or lifestyle coaches), it may be challenging to scale them for widespread use.

Taken together, the above findings suggest that behavioral interventions may influence cellular aging. Given the limitations of existing research, well-powered, pre-registered randomized controlled trials are needed to verify such findings in a broader population. Finally, interventions to impact telomere length that are low-cost, accessible, selfadministered, relatively brief, and nonstigmatizing would arm lay people with the tools necessary to improve their own psychological and biological health.

\subsection{Present study}

Theoretical work has called for more "shortitudinal" investigations-namely, studies that employ repeated assessments across relatively short time lags - to estimate the optimal timing for assessment of a wide array of outcomes (Dormann \& Griffin, 2015). In the present study, we sought to explore whether a shortitudinal prosocial behavior intervention could positively impact human telomere length and well-being. We employed an experimental paradigm that involves performing acts of kindness for others, which has been shown previously to improve psychological flourishing (Nelson et al., 2016) and to elicit favorable changes in gene expression (i.e., a downregulation in the conserved transcriptional response to adversity; Nelson-Coffey et al., 2017), relative to a neutral control condition (i.e., tracking daily activities). Pre-registration for this study is available on the Open Science Framework at https://osf.io/93ck7/.

\subsubsection{Psychological hypotheses}

We predicted that, relative to participants who performed a neutral task, those who performed kind acts for others would improve in psychological well-being (e.g., greater life satisfaction, more psychological flourishing, and less loneliness) across the intervention period, relative to controls. We also predicted that participants who performed kind acts for others would report increases in weekly measures of social connection and positive affect, and decreases in weekly measures of negative affect and perceived stress.

\subsubsection{Biological hypotheses}

We also hypothesized that individuals who performed kind acts for others would demonstrate significant reductions in the rates of telomere shortening relative to controls. Furthermore, we predicted that the effect of performing acts of kindness for others on telomere length change would be mediated by increases in social connectedness and decreases in loneliness and perceived stress.

\section{Method}

\subsection{Participants}

Community adults $(N=230)$ were recruited through email advertisement, flyers, and community fairs to participate in a study of positive activities and health. See Table 1 for baseline sample characteristics. Participants were eligible if they were 21 years of age or older and not currently taking antidepressant medication, and received $\$ 100$ compensation for completing all timepoints. The majority (73\%) identified as female $\left(M_{\text {age }}=34.8\right.$ years, $S D=11.23$, range $\left.=21-83\right)$ and highly educated $(52.2 \%)$, and a plurality were White (42.6\%). All study procedures were approved by the University of California, Riverside, Institutional Review Board, and all participants provided written informed consent.

\subsection{Design and procedure}

Using a single-blind design, participants were randomly assigned to participate in one of three possible conditions that varied only with respect to their activity instructions. Intervention instructions were adapted from prior work (i.e., Nelson et al., 2016; Nelson-Coffey et al., 2017) and are available in full in the Supplemental Materials. The kindness-to-others group was instructed to perform three acts of kindness for other people, all three in one day, each week for 4 weeks. The control group was instructed to keep track of their usual daily activities on one day each week for 4 weeks. Finally, following prior studies using this paradigm (i.e., Nelson et al., 2016; Nelson-Coffey et al., 2017), we included a kindness-to-self active comparison group, which received instructions to perform three acts of kindness for themselves, all three in one day, each week for 4 weeks. Each week during the intervention period (see Fig. 1), participants logged on to the study website (either in-lab [i.e., $\mathrm{T}_{1}$ and $\mathrm{T}_{5}$ ] or from home [i.e., $\mathrm{T}_{2}, \mathrm{~T}_{3}$, and $\mathrm{T}_{4}$ ]) to complete outcome measures, report on the previous week's activities, and receive instructions for the following week's activities ( $T_{1}$ through $T_{4}$ only). Finally, at the 2-week follow up $\left(\mathrm{T}_{6}\right)$, participants logged on to the study website to complete one final assessment of outcome measures.

At $\mathrm{T}_{1}$ and $\mathrm{T}_{5}$ (i.e., baseline and post-intervention), participants came 
Table 1

Baseline sample characteristics.

\begin{tabular}{|c|c|c|c|c|}
\hline Variable & $\begin{array}{l}\text { Control }(n \\
=84)\end{array}$ & $\begin{array}{l}\text { Self-Kindness } \\
(n=74)\end{array}$ & $\begin{array}{l}\text { Other- } \\
\text { Kindness ( } n= \\
72)\end{array}$ & $p^{\mathrm{a}}$ \\
\hline Age (mean \pm SD years) & $\begin{array}{l}37.02 \\
(13.04)\end{array}$ & 33.18 (9.94) & $33.86(9.84)$ & .07 \\
\hline Sex (\% Female) & $75.0 \%$ & $73.0 \%$ & $70.8 \%$ & .84 \\
\hline $\begin{array}{l}\text { Race/ethnicity (\% self- } \\
\text { identified) }\end{array}$ & & & & .93 \\
\hline Asian/Asian American & $9.5 \%$ & $12.2 \%$ & $13.9 \%$ & \\
\hline Black/African American & $3.6 \%$ & $5.4 \%$ & $5.6 \%$ & \\
\hline $\begin{array}{l}\text { Hawaiian/Pacific } \\
\text { Islander }\end{array}$ & $1.2 \%$ & $1.4 \%$ & $2.8 \%$ & \\
\hline White & $46.4 \%$ & $41.9 \%$ & $38.9 \%$ & \\
\hline Hispanic/Latinx & $32.1 \%$ & $32.4 \%$ & $25.0 \%$ & \\
\hline Middle Eastern & $1.2 \%$ & $2.7 \%$ & $5.6 \%$ & \\
\hline Other/More than One & $4.8 \%$ & $4.1 \%$ & $6.9 \%$ & \\
\hline $\begin{array}{c}\text { American Indian/ } \\
\text { Alaskan Native }\end{array}$ & $1.2 \%$ & $0.0 \%$ & $1.4 \%$ & \\
\hline Education level & & & & .52 \\
\hline $\begin{array}{l}\text { (1) Did not finish high } \\
\text { school }\end{array}$ & $0.0 \%$ & $2.7 \%$ & $2.8 \%$ & \\
\hline (2) High school diploma & $1.2 \%$ & $4.1 \%$ & $1.4 \%$ & \\
\hline (3) Some College & $15.5 \%$ & $14.9 \%$ & $13.9 \%$ & \\
\hline (4) 4-Year Degree & $26.2 \%$ & $31.5 \%$ & $26.4 \%$ & \\
\hline $\begin{array}{l}\text { (5) Graduate or } \\
\text { Professional Degree }\end{array}$ & $57.1 \%$ & $43.2 \%$ & $55.6 \%$ & \\
\hline \multicolumn{5}{|l|}{ Employment ${ }^{\mathrm{b}}$ (\% Yes) } \\
\hline (1) Full-time & $59.5 \%$ & $63.5 \%$ & $58.3 \%$ & .80 \\
\hline (2) Part-time & $9.5 \%$ & $10.8 \%$ & $11.1 \%$ & .94 \\
\hline $\begin{array}{l}\text { (3) Full-time college/ } \\
\text { university student }\end{array}$ & $25 \%$ & $23 \%$ & $25 \%$ & .95 \\
\hline (4) Self-employed & $2.4 \%$ & $4.1 \%$ & $2.8 \%$ & .82 \\
\hline (5) Unemployed & $4.8 \%$ & $4.1 \%$ & $5.6 \%$ & .91 \\
\hline (6) Retired & $2.4 \%$ & $0.0 \%$ & $1.4 \%$ & .42 \\
\hline (7) Other & $4.8 \%$ & $5.4 \%$ & $5.6 \%$ & .97 \\
\hline Hormone use (\% Yes) & $22.6 \%$ & $25.7 \%$ & $31.9 \%$ & .41 \\
\hline $\begin{array}{l}\text { Baseline illness } \\
\text { symptoms (\% Yes) }\end{array}$ & $8.3 \%$ & $8.1 \%$ & $2.8 \%$ & .30 \\
\hline $\begin{array}{l}\text { Post-intervention illness } \\
\text { symptoms (\% Yes) }\end{array}$ & $6.0 \%$ & $6.8 \%$ & $4.2 \%$ & .79 \\
\hline Body mass index & $\begin{array}{l}26.24 \\
(6.05)\end{array}$ & $28.85(8.13)$ & $26.09(6.88)$ & $.03 *$ \\
\hline $\begin{array}{l}\text { Life Satisfaction (mean } \\
\quad \pm \text { SD) }\end{array}$ & $4.82(1.32)$ & $4.92(1.17)$ & $4.73(1.12)$ & .61 \\
\hline Flourishing (mean $\pm \mathrm{SD}$ ) & $3.27(0.66)$ & $3.30(0.72)$ & $3.28(0.61)$ & .95 \\
\hline Happiness (mean \pm SD) & $4.81(1.33)$ & $4.99(1.21)$ & $4.88(1.16)$ & .67 \\
\hline Loneliness (mean \pm SD) & $1.97(0.52)$ & $2.01(0.52)$ & $2.00(0.61)$ & .91 \\
\hline $\begin{array}{l}\text { Baseline LTL (mean } \pm \\
\quad \text { SD) }\end{array}$ & $1.43(0.25)$ & $1.44(0.27)$ & $1.45(0.29)$ & .91 \\
\hline $\begin{array}{l}\text { Number of kind acts } \\
\quad \text { reported }^{\mathrm{c}}(\text { mean } \pm \mathrm{SD})\end{array}$ & N/A & $10.18(3.31)$ & $10.10(3.05)$ & .83 \\
\hline
\end{tabular}

Note. LTL = leukocyte telomere length.

a Omnibus test statistic from ANOVA (continuous variables), $\chi^{\mathrm{b}}$ (categorical variables), or $t$-test (for number of kind acts reported).

b Employment categories were not mutually exclusive.

c Possible range was 0-12 across the intervention period; participants in the control condition were not asked to report number of kind acts.

to the lab to provide a small dried blood spot (DBS) sample via finger prick for analysis of telomere length and to complete self-report measures of psychological outcomes (e.g., mental health flourishing, life satisfaction) and potential mediators (e.g., social connection, affect). Immediately following completion of these questionnaires, participants were provided intervention instructions for their randomly assigned activity.

At all other timepoints (i.e., $\mathrm{T}_{2}, \mathrm{~T}_{3}, \mathrm{~T}_{4}$, and $\mathrm{T}_{6}$ ), participants were emailed web links to complete weekly surveys on their home computers or mobile devices (and to be debriefed; $\mathrm{T}_{6}$ only).

\subsection{Measures}

\subsubsection{Psychological measures}

2.3.1.1. Life satisfaction. At $\mathrm{T}_{1}, \mathrm{~T}_{5}$, and $\mathrm{T}_{6}$, participants reported their current satisfaction with their life in general using the Satisfaction With Life Scale (SWLS; Diener et al., 1985). The SWLS consists of five questions (e.g., "In most ways my life is close to my ideal," "I am satisfied with my life") rated on 7-point Likert-type scales ( 1 = strongly disagree, 7 = strongly agree). Across measurements, Cronbach's $\alpha$ ranged from 0.87 to 0.90 .

2.3.1.2. Flourishing. The Mental Health Continuum-Short Form (MHCSF; Keyes, 2002) measures the extent to which participants are experiencing flourishing mental health. At $\mathrm{T}_{1}, \mathrm{~T}_{5}$, and $\mathrm{T}_{6}$, participants responded to 14 items (e.g., "How often did you feel that you liked most parts of your personality?") assessing components of emotional, social, and personal well-being on a scale from 0 (never) to 5 (every day). Cronbach's $\alpha$ s ranged from 0.89 to 0.94 across timepoints.

2.3.1.3. Loneliness. The 20 -item Revised UCLA Loneliness Scale (Russell et al., 1980) assesses perceived loneliness. At $\mathrm{T}_{1}, \mathrm{~T}_{5}$, and $\mathrm{T}_{6}$, participants indicated how frequently each item described them on a 4-point Likert-type scale $(0=$ never, $3=$ often). Items include "I feel in tune with people around me" and "I feel isolated from others." Across timepoints, Cronbach's $\alpha$ s ranged from 0.92 to 0.94 .

2.3.1.4. Positive and negative affect. Weekly emotions were assessed using the 9-item Affect-Adjective Scale (Diener \& Emmons, 1984), which taps a range of positive emotions (happy, pleased, joyful, enjoyment/fun) and negative emotions (worried/anxious, angry/hostile, frustrated, depressed/blue, unhappy). At all timepoints, participants rated the extent to which they have experienced the emotions in the past week on a 7-point Likert scale $(0=$ not at all, $1=$ slightly, $2=$ somewhat, $3=$ moderately, $4=$ much, $5=$ very much, $6=$ extremely). Across timepoints, Cronbach's $\alpha$ s ranged from 0.90 to 0.95 for positive emotions, and 0.82 to 0.89 for negative emotions.

2.3.1.5. Social connectedness. We assessed participants' feelings of social connectedness at each timepoint with the relatedness subscale from the Balanced Measure of Need Satisfaction (BMPN; Sheldon \& Hilpert, 2012). This 6-item measure (with 3 positively worded and 3 negatively worded items each) assesses connectedness over the past week (e.g., "I felt a sense of contact with people who care for me"). Participants rated their level of agreement with each item on 5-point Likert-type scale ( $1=$ no agreement, $3=$ some agreement, $5=$ much agreement). Cronbach's $\alpha \mathrm{s}$ ranged from 0.71 to 0.85 across all measurements.

2.3.1.6. Perceived stress. At each timepoint, participants reported their level of stress using the 10-item Perceived Stress Scale (Cohen et al., 1983) adapted to assess stress over the past week, rather than month. Using a 5-point Likert-type scale ( $1=$ never, $5=$ very often $)$, they rated the frequency of stress, such as "How often in the past week have you felt you could not cope with all the things you have to do?" Cronbach's $\alpha$ s ranged from 0.87 to 0.90 across all measurements.

\subsubsection{Biological measures}

2.3.2.1. Leukocyte telomere length (LTL). Genomic DNA was extracted from six 3-mm diameter cutouts from dried blood spot samples using QIAamp DNA Investigator Kit (cat\# 56504) according to manufacturer's instructions. DNA concentration was quantified by PicoGreen Assay using ThermoFisher NanoDropTM 3300. The average DNA concentration was $4.5 \mathrm{ng} / \mu \mathrm{l}$.

The telomere length measurement assay is adapted from the published original PCR-based method by Cawthon (Cawthon, 2002; Lin 


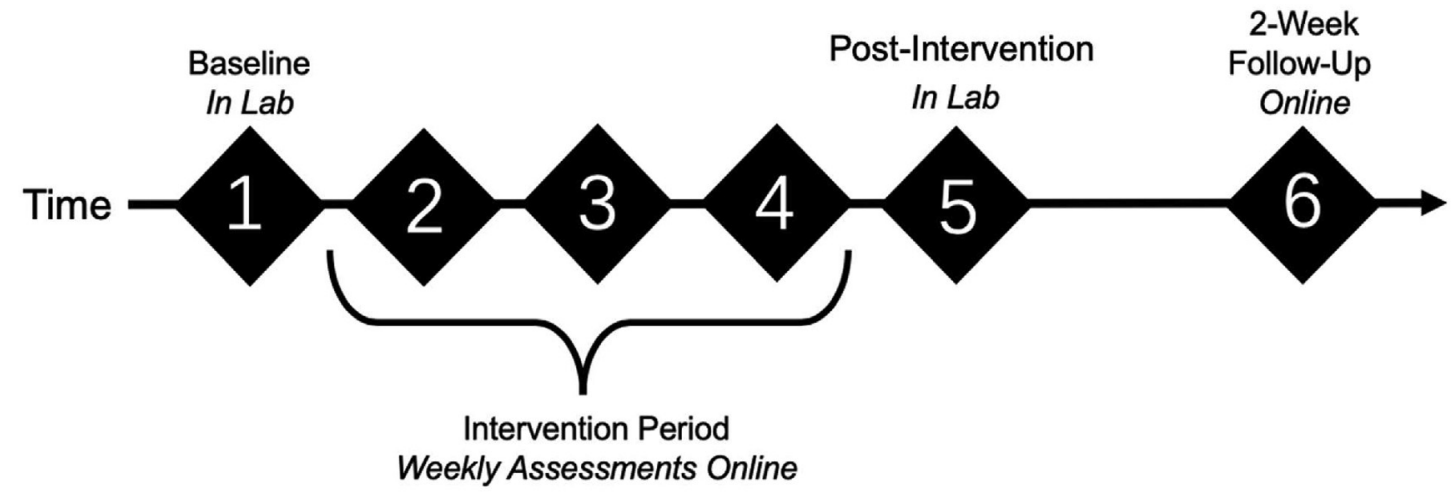

Fig. 1. Study Timeline. Note. $\mathrm{T}_{1}$ (baseline) through $\mathrm{T}_{5}$ (post-intervention) occurred at weekly intervals; $\mathrm{T}_{6}\left(2\right.$-week follow-up) occurred 2 weeks after $\mathrm{T}_{5}$.

et al., 2010; See Supplemental Materials for assay method details).

To control for batch variance, the $\mathrm{T} / \mathrm{S}$ ratio for each sample was measured in two separate runs. T/S values were then adjusted based on initial systematic differences between the two runs as determined by comparing the reference DNA standard curves. When the duplicate T/S values varied by more than $7 \%$ after adjustments (i.e., in $35 \%$ of samples), the sample was assayed for a third or fourth time and the two closest values were reported. Samples were run in batches of 96 wells. The batch differences were adjusted by repeating a subset of study samples from each plate and subsequently adjusting runs 1 and 2 accordingly. Using this method, the average CV for this study was $2.15 \%$.

\subsubsection{Analytic approach}

We pre-registered our analytic plan, including our planned covariates for the biological analyses, on the Open Science Framework (https://osf. io/93ck7/). We considered analyses involving the self-kindness condition as exploratory, given our lack of strong directional hypotheses regarding its effects on psychological outcomes or telomere length. See Supplemental Materials for additional measures not reported here. Based on the Shapiro-Wilk test, $\mathrm{T} / \mathrm{S}$ values were normally distributed at baseline ( $W=0.9917, \mathrm{p}=.22$ for null hypothesis), but not at postintervention ( $W=0.9812, \mathrm{p}=.005$ for null hypothesis). Thus, $\mathrm{T} / \mathrm{S}$ ratio scores at both timepoints were log-transformed prior to analysis. Because $n=7$ participants did not return at the follow-up, our final analytic sample for telomere analyses included 223 participants with both baseline and follow-up data. Participants lost to follow-up did not differ between conditions, $\chi^{2}=0.46, p=.79$.

\section{Results}

\subsection{Biological outcome}

Using the NLME package in R Studio version 1.3.959, we ran a linear mixed-effects model analysis, adjusted for our pre-registered covariates (i.e., age, sex, BMI, illness symptoms at baseline and post-intervention, and hormone use), to examine the effect of condition on our primary biological outcome of change in LTL (i.e., our pre-registered biological hypothesis; see Fig. 2). Contrary to our prediction, participants in the other-kindness condition did not show significantly different rates of change in LTL relative to controls ( $b$ [SE] $=-0.01$ [0.007], 95\% CI [-0.02 $-0.00], p=.126$ ). Results became marginally significant (in the direction opposite to our hypothesis) when this model was run without covariates in the model, $(b$ [SE] $=-0.012$ [0.007], 95\% CI [-0.02 - 0.00], $p=.078$ ), and when excluding individuals reporting illness symptoms at either timepoint, $(b[\mathrm{SE}]=-0.013$ [0.007], 95\% CI [-0.03-0.00], $p=.062$ ).

\subsubsection{Exploratory biological analyses}

Across the full sample, telomere length increased from baseline, and a one-sample $t$-test on the change scores suggested this finding was marginal, $t(222)=1.77, p=.08$. LTL did not differ by sex at baseline, $t(228)$ $=0.10, p=.92$, or post-intervention, $t(221)=0.02, p=.96$.

3.1.1.1. Kindness to self condition differences. A linear mixed-effects model analysis, adjusted for our pre-registered covariates (i.e., age, sex, BMI, illness symptoms at baseline and post-intervention, and hormone use) revealed that, relative to controls, participants in the self-kindness

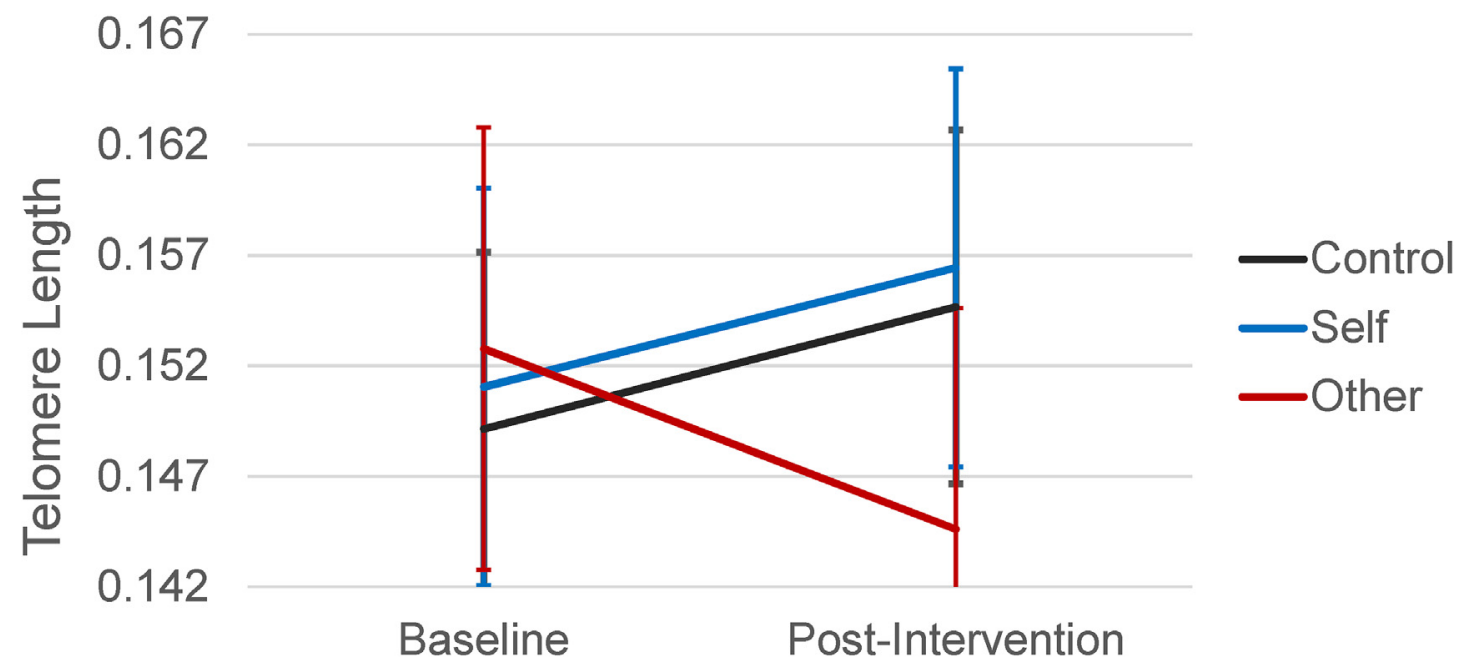

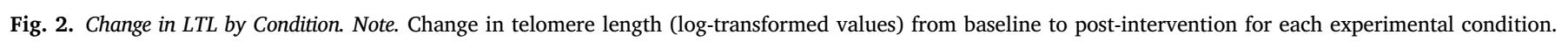


condition did not report significant changes in LTL over time, $b$ [SE] $=$ -0.002 [0.007], 95\% CI [-0.01 - 0.01], $p=.776$.

In light of the trend evident in Fig. 2 (i.e., in the opposite direction from our pre-registered hypothesis), we further explored the effect of condition on LTL using regressed change analyses. Using this approach, and controlling for our pre-registered covariates and baseline LTL, we found that participants in the other-kindness condition demonstrated significantly shorter LTL at post-intervention than did participants in the control condition, $b$ [SE] $=-0.013$ [0.006], 95\% CI [-0.02 - 0.00], $p=$ .047. Participants in the self-kindness condition, however, did not demonstrate significantly different LTL than did controls, $b[\mathrm{SE}]=-0.003$ [0.006], 95\% CI [-0.02-0.01], $p=.665$.

\subsection{Psychological outcomes}

Using planned contrasts, we tested whether participants in the otherkindness condition reported greater change scores in psychological variables relative to the control group (i.e., our pre-registered psychological hypotheses). Contrary to predictions, no significant differences between other-kindness and control were detected for flourishing, $t(224)=0.66, p$ $=.51$, life satisfaction, $t(224)=0.30, p=.76$, or loneliness, $t(223)=$ $-0.91, p=.37$, for change scores between baseline and post-intervention (see Table 2). A similar pattern emerged when examining change scores between baseline and follow-up, with no significant differences between other-kindness and control detected for flourishing, $t(128)=0.74, p=.46$ life satisfaction, $t(133)=1.56, p=.12$, or loneliness, $t(127)=-1.37, p=$ 17 .

Additionally, relative to controls, participants in the other-kindness condition did not report greater positive affect, $t(227)=0.54, p=.59$, greater connectedness, $t(167)=-0.14, p=.89$, less negative affect, $t(227)=-0.45, p=.66$, or lower stress, $t(167)=0.96, p=.34$, on average across the intervention period (e.g., averaged from $\mathrm{T}_{2}$ - $\mathrm{T}_{5}$; see Table 3 ). Given the lack of association between experimental condition, our hypothesized potential mediator variables, and our primary psychological outcomes of interest, we did not proceed to test our pre-registered mediation models.

\subsubsection{Exploratory psychological analyses}

3.2.1.1. Kindness to self condition differences. We used post-hoc contrasts to test whether the self-kindness group differed from either the control group or the other-kindness group on our psychological outcomes of interest. Relative to controls, participants in the self-kindness group reported significantly less loneliness (i.e., lower change scores) at the postintervention, $t(223)=-2.06, p=.04$, but not at the follow up, $t(127)=$ $-1.40, p=.17$. No other significant differences were detected between the self-kindness and control groups for change scores of flourishing or life satisfaction between baseline and post-intervention, $p s>.58$, or baseline and follow up, $p s>.68$. Further, relative to controls, participants in the self-kindness condition did not report improved positive affect, connectedness, negative affect, or stress, on average, across the intervention period ( $p s>$.09). Finally, no significant differences emerged between the self-kindness and other-kindness groups on these outcomes, $p s>.27$ (see Tables 2 and 3).

3.2.1.2. Growth modeling. To further explore the trajectory of our psychological variables across multiple timepoints, we used multilevel growth curve modeling to account for repeated measures nested within participant. Relative to controls, participants in the other-kindness condition reported significant decreases in loneliness from baseline through the 2-week follow up, $\gamma_{11}=-0.059, p=.034$ and participants in the selfkindness condition reported a trend in the same direction, $\gamma_{12}=-0.051, p$ $=.064$ (see Table 4 and Fig. 3). However, relative to controls, participants in the other-kindness and self-kindness conditions did not report greater increases in life satisfaction, $p s>.13$, or flourishing, $p s>.44$, across time.

\subsection{Additional exploratory analyses}

3.3.1. Relationship between psychological variables and telomere length

We explored raw and partial correlations (i.e., adjusted for our covariates) between baseline telomere length and participant demographic and psychological variables. We also examined whether change in any psychological variables across conditions correlated with change in telomere length from baseline to post-intervention. LTL correlated negatively with age $(r=-.45, p<.0001)$, but no significant associations were found between LTL and any other demographic or psychological variable (see Supplemental Materials for analyses.)

\section{Discussion}

\subsection{Biological outcome}

Our hypothesis with regard to telomere length change was not supported using our pre-registered analytic plan. Primary analyses indicated no effect, and exploratory secondary analyses of regressed change suggested a pattern in the opposite direction-that engaging in kindness to others may have paradoxically led to shorter telomere length. However, the explanation for this result is unclear, and may stem from the interpretive complexities of regressed change analyses (e.g., because baseline values influence both predictors and outcomes) or from systematic psychobiological effects that are not presently understood and require further replication and mechanistic clarification in future studies. Importantly, we did not find evidence in the psychological assessments

Table 2

Planned contrasts and post-hoc tests by condition and timepoint for pre-post measures.

\begin{tabular}{|c|c|c|c|c|c|c|c|c|c|c|c|c|c|c|c|}
\hline \multirow[t]{2}{*}{ Variable } & \multicolumn{2}{|c|}{$\begin{array}{l}\text { Kindness to Others } \\
\text { Contrast 1: }+1 \\
\text { Contrast 2: }+1 \\
\text { Contrast 3: } 0\end{array}$} & \multicolumn{2}{|c|}{$\begin{array}{l}\text { Kindness to Self } \\
\text { Contrast 1: } 0 \\
\text { Contrast 2: } 1 \\
\text { Contrast } 3:+1\end{array}$} & \multicolumn{2}{|c|}{$\begin{array}{l}\text { List Daily Activities (Control) } \\
\text { Contrast 1: } 1 \\
\text { Contrast 2: } 0 \\
\text { Contrast 3: } 1\end{array}$} & \multicolumn{3}{|c|}{ Contrast 1} & \multicolumn{3}{|c|}{ Contrast 2} & \multicolumn{3}{|c|}{ Contrast 3} \\
\hline & $\mathrm{M}(\mathrm{SD})$ & $\mathrm{n}$ & $\mathrm{M}(\mathrm{SD})$ & $\mathrm{n}$ & $\mathrm{M}(\mathrm{SD})$ & $\mathrm{n}$ & $\mathrm{t}$ & $\mathrm{p}$ & $\mathrm{r}$ & $\mathrm{t}$ & $\mathrm{p}$ & $\mathrm{r}$ & $\mathrm{t}$ & $\mathrm{P}$ & $\mathrm{r}$ \\
\hline \multicolumn{16}{|c|}{ Post-Intervention } \\
\hline Life Sat & $4.62(1.37)$ & 71 & $4.71(1.44)$ & 73 & $4.68(1.48)$ & 83 & -0.23 & .82 & .02 & -0.35 & .73 & .02 & 0.14 & .89 & .01 \\
\hline Flourishing & $3.33(0.70)$ & 71 & $3.26(0.75)$ & 73 & $3.26(0.71)$ & 83 & 0.61 & .54 & .04 & 0.56 & .57 & .04 & 0.03 & .97 & .00 \\
\hline Loneliness & $1.95(0.57)$ & 70 & $1.94(0.56)$ & 73 & $1.99(0.56)$ & 83 & -0.39 & .70 & .03 & 0.10 & .92 & .01 & -0.50 & .62 & .03 \\
\hline $\begin{array}{l}\text { LTL } \\
\text { Follow Up }\end{array}$ & $1.45(0.24)$ & 69 & $1.46(.26)$ & 72 & $1.43(0.30)$ & 82 & -0.49 & .63 & .03 & -0.69 & .49 & .05 & 0.23 & .82 & .02 \\
\hline Life Sat & $5.09(1.24)$ & 39 & $5.16(1.27)$ & 42 & $5.03(1.34)$ & 55 & 0.20 & .84 & .02 & -0.24 & .81 & .02 & 0.47 & .64 & .04 \\
\hline Flourishing & $3.35(0.81)$ & 38 & $3.38(0.81)$ & 40 & $3.30(0.85)$ & 53 & 0.31 & .76 & .03 & -0.13 & .90 & .01 & 0.45 & .66 & .04 \\
\hline Loneliness & $1.82(0.62)$ & 38 & $1.92(0.58)$ & 39 & $1.94(0.56)$ & 53 & -0.94 & .35 & .08 & -0.79 & .43 & .07 & -0.09 & .93 & .01 \\
\hline
\end{tabular}

Note. LTL = leukocyte telomere length; Life Sat = life satisfaction.

${ }^{\dagger} p \leq .10 .{ }^{*} p \leq .05 .{ }^{* *} p \leq .01 .{ }^{* * *} p \leq .001$. 
Table 3

Planned contrasts and post-hoc tests by condition and timepoint for weekly measures.

\begin{tabular}{|c|c|c|c|c|c|c|c|c|c|c|c|c|c|c|c|}
\hline \multirow[t]{2}{*}{ Variable } & \multicolumn{2}{|c|}{$\begin{array}{l}\text { Kindness to Others } \\
\text { Contrast } 1:+1 \\
\text { Contrast } 2:+1 \\
\text { Contrast 3: } 0\end{array}$} & \multicolumn{2}{|c|}{$\begin{array}{l}\text { Kindness to Self } \\
\text { Contrast 1: } 0 \\
\text { Contrast 2: } 1 \\
\text { Contrast 3: }+1\end{array}$} & \multicolumn{2}{|c|}{$\begin{array}{l}\text { List Daily Activities (Control) } \\
\text { Contrast 1: } 1 \\
\text { Contrast 2: } 0 \\
\text { Contrast 3: } 1\end{array}$} & \multicolumn{3}{|c|}{ Contrast 1} & \multicolumn{3}{|c|}{ Contrast 2} & \multicolumn{3}{|c|}{ Contrast 3} \\
\hline & $\mathrm{M}(\mathrm{SD})$ & $\mathrm{n}$ & $\mathrm{M}(\mathrm{SD})$ & $\mathrm{n}$ & $\mathrm{M}(\mathrm{SD})$ & $\mathrm{n}$ & $\mathrm{t}$ & $\mathrm{p}$ & $\mathrm{r}$ & $\mathrm{t}$ & $\mathrm{p}$ & $\mathrm{r}$ & $\mathrm{t}$ & $\mathrm{p}$ & $\mathrm{r}$ \\
\hline \multicolumn{16}{|l|}{ Week 1/Baseline } \\
\hline Positive Affect & $4.63(1.16)$ & 72 & $4.83(1.15)$ & 74 & $4.67(1.11)$ & 84 & -0.26 & .79 & .02 & -1.10 & .27 & .07 & 0.88 & .38 & .06 \\
\hline Negative Affect & 2.87 (1.09) & 72 & $2.94(1.14)$ & 74 & $2.80(1.09)$ & 84 & 0.36 & .72 & .02 & -0.42 & .68 & .03 & 0.80 & .43 & .05 \\
\hline Connectedness & $3.81(0.73)$ & 72 & $3.70(0.80)$ & 74 & $3.86(0.73)$ & 84 & -0.41 & .69 & .03 & 0.90 & .37 & .06 & -1.34 & .18 & .09 \\
\hline $\begin{array}{l}\text { Perceived Stress } \\
\text { Week } 2\end{array}$ & $2.64(0.66)$ & 72 & $2.66(0.66)$ & 74 & $2.62(0.72)$ & 84 & 0.17 & .87 & .01 & -0.17 & .86 & .01 & 0.35 & .73 & .02 \\
\hline Positive Affect & $4.63(1.19)$ & 62 & $4.65(1.32)$ & 62 & $4.67(1.06)$ & 75 & -0.23 & .83 & .02 & -0.11 & .91 & .01 & -0.10 & .92 & .01 \\
\hline Negative Affect & $2.68(1.00)$ & 62 & $2.81(1.04)$ & 62 & $2.52(0.93)$ & 75 & 0.97 & .34 & .07 & -0.73 & .47 & .05 & 1.73 & $.09^{\dagger}$ & .12 \\
\hline Connectedness & $3.85(0.74)$ & 62 & $3.66(0.86)$ & 62 & $3.86(0.81)$ & 75 & -0.07 & .94 & .00 & 1.30 & .20 & .09 & -1.43 & .15 & .09 \\
\hline $\begin{array}{l}\text { Perceived Stress } \\
\text { Week } 3\end{array}$ & \multicolumn{5}{|c|}{ Week 3} & 75 & 0.67 & .50 & .05 & -0.14 & .89 & .01 & 0.83 & .41 & .06 \\
\hline Positive Affect & $4.79(1.22)$ & 56 & $4.90(1.33)$ & 61 & $4.85(1.24)$ & 79 & -0.29 & .77 & .02 & -0.48 & .63 & .03 & 0.22 & .83 & .02 \\
\hline Negative Affect & 2.57 (1.05) & 56 & $2.66(1.13)$ & 61 & $2.52(0.92)$ & 79 & 0.25 & .81 & .02 & -0.50 & .62 & .04 & 0.79 & .43 & .06 \\
\hline Connectedness & $3.92(0.68)$ & 56 & $3.81(0.81)$ & 61 & $4.01(0.77)$ & 79 & -0.69 & .50 & .05 & 0.75 & .45 & .05 & -1.52 & .13 & .11 \\
\hline $\begin{array}{l}\text { Perceived Stress } \\
\text { Week } 4\end{array}$ & $2.60(0.67)$ & 56 & $2.53(0.68)$ & 61 & $2.48(0.69)$ & 79 & 1.03 & .30 & .07 & 0.54 & .59 & .04 & 0.47 & .64 & .03 \\
\hline Positive Affect & 4.65 (1.39) & 54 & 4.93 (1.35) & 60 & $4.75(1.31)$ & 72 & -0.40 & .69 & .03 & -1.08 & .28 & .08 & 0.75 & .46 & .06 \\
\hline Negative Affect & $2.49(1.18)$ & 54 & $2.59(1.10)$ & 60 & $2.55(1.14)$ & 72 & -0.26 & .80 & .02 & -0.45 & .65 & .03 & 0.21 & .83 & .02 \\
\hline Connectedness & $3.95(0.81)$ & 54 & $3.89(0.84)$ & 60 & $3.95(0.76)$ & 72 & -0.01 & .99 & .00 & 0.36 & .72 & .03 & -0.39 & .69 & .03 \\
\hline Perceived Stress & $2.63(0.71)$ & 54 & $2.58(0.70)$ & 60 & $2.48(0.76)$ & 72 & 1.14 & .26 & .08 & 0.36 & .72 & .03 & 0.79 & .43 & .06 \\
\hline \multicolumn{16}{|c|}{ Week 5/Post-Intervention } \\
\hline Positive Affect & $4.89(1.21)$ & 71 & $5.00(1.26)$ & 73 & $4.72(1.33)$ & 83 & 0.83 & .41 & .06 & -0.53 & .59 & .04 & 1.39 & .17 & .09 \\
\hline Negative Affect & $2.31(0.99)$ & 71 & $2.48(0.97)$ & 73 & $2.47(1.16)$ & 83 & -0.96 & .34 & .06 & -0.98 & .33 & .07 & 0.06 & .96 & .00 \\
\hline Connectedness & $4.03(0.76)$ & 71 & $4.03(0.70)$ & 73 & $4.02(0.78)$ & 83 & 0.09 & .93 & .01 & .01 & .99 & .00 & 0.08 & .94 & .01 \\
\hline $\begin{array}{l}\text { Perceived Stress } \\
\text { Week } 6 / \text { Follow }\end{array}$ & $2.50(0.76)$ & 71 & $2.51(0.70)$ & 73 & $2.56(0.82)$ & 83 & -0.44 & .66 & .03 & -0.07 & .95 & .00 & -0.37 & .71 & .02 \\
\hline Positive Affect & $5.18(1.44)$ & 39 & $4.98(1.42)$ & 42 & $4.93(1.35)$ & 55 & 0.86 & .39 & .07 & 0.64 & .53 & .06 & 0.19 & .85 & .02 \\
\hline Negative Affect & 2.64 (1.37) & 39 & $2.65(1.06)$ & 42 & $2.60(1.09)$ & 55 & 0.18 & .86 & .02 & -0.04 & .97 & .00 & 0.23 & .82 & .02 \\
\hline Connectedness & $4.09(0.86)$ & 39 & $3.89(0.86)$ & 41 & $3.90(0.87)$ & 55 & 1.07 & .29 & .09 & 1.01 & .31 & .00 & -0.02 & .99 & .00 \\
\hline Perceived Stress & $2.50(0.83)$ & 38 & $2.52(0.69)$ & 40 & $2.49(0.75)$ & 53 & 0.09 & .93 & .01 & -0.11 & .91 & .01 & 0.21 & .83 & .02 \\
\hline
\end{tabular}

${ }^{\dagger} p \leq .10 .{ }^{*} p \leq .05 .{ }^{* *} p \leq .01 .{ }^{* * *} p \leq .001$.

Table 4

Model parameters (standard errors) and goodness of fit for linear change for loneliness from baseline to follow-up $\left(\mathrm{T}_{6}\right)$.

\begin{tabular}{|c|c|c|c|c|}
\hline & \multirow[b]{2}{*}{ Effect } & \multirow[b]{2}{*}{ Parameter } & \multicolumn{2}{|l|}{ Loneliness } \\
\hline & & & $\begin{array}{l}\text { Model 1: } \\
\text { Unconditional } \\
\text { Growth }\end{array}$ & $\begin{array}{l}\text { Model 2: } \\
\text { Kindness } \\
\text { Condition vs } \\
\text { Control }\end{array}$ \\
\hline \multirow{6}{*}{$\begin{array}{l}\text { Fixed } \\
\text { Effects }\end{array}$} & Intercept & $\gamma_{00}$ & $2.02(0.40)^{* * *}$ & $1.97(0.07)^{* * *}$ \\
\hline & Time & $\gamma_{10}$ & $-0.03(0.01)^{*}$ & 0.002 \\
\hline & Other-Kindness & $\gamma_{01}$ & - & $0.09(0.10)$ \\
\hline & Self-Kindness & $\gamma_{02}$ & - & $0.08(0.10)$ \\
\hline & $\begin{array}{l}\text { Time * Other- } \\
\text { Kindness }\end{array}$ & $\gamma_{11}$ & - & $-0.06(0.03)^{*}$ \\
\hline & $\begin{array}{l}\text { Time * Self- } \\
\text { Kindness }\end{array}$ & $\gamma_{12}$ & - & $-0.05(0.03)^{\dagger}$ \\
\hline \multirow{3}{*}{$\begin{array}{l}\text { Random } \\
\text { Effects }\end{array}$} & Level 1 & $\sigma_{\varepsilon}^{2}$ & 0.04 & 0.04 \\
\hline & Level 2 & $\sigma^{2}$ & 0.28 & 0.28 \\
\hline & & $\sigma^{2}$ & 0.87 & 0.88 \\
\hline \multirow{9}{*}{$\begin{array}{c}\text { Goodness } \\
\text { of Fit }\end{array}$} & Deviance & & 451.39 & 445.74 \\
\hline & Akaike & & 459.39 & 461.74 \\
\hline & Information & & & \\
\hline & Criterion & & & \\
\hline & Bayesian & & 476.88 & 496.73 \\
\hline & Information & & & \\
\hline & Criterion & & & \\
\hline & $\Delta \chi^{2}$ & & & 5.64 \\
\hline & $\Delta \mathrm{df}$ & & & 4 \\
\hline
\end{tabular}

Note. In Model 1 , the intercept parameter estimate $\left(\gamma_{00}\right)$ represents average loneliness at baseline across the sample. In Model 2, the intercept parameter estimate $\left(\gamma_{00}\right)$ represents average loneliness for those in the control condition. ${ }^{\dagger} p \leq .10 .{ }^{*} p \leq .05 .{ }^{* *} p \leq .01 .{ }^{* * *} p \leq .001$. that the other-kindness group was under more stress than the self-kindness or control participants during the intervention period.

Across conditions, we found a trend toward telomere elongation across time in our study. Although this finding could be noise and/or measurement error, it may also reflect a systematic effect with unknown mechanisms. Notably, telomere elongation has been reported elsewhere (e.g., Aviv et al., 2009), and several longitudinal studies reported telomere elongation in over $20 \%$ of their samples across spans of up to 5 years (Berglund et al., 2016; Farzaneh-Far et al., 2010). More relevant to our study, one small trial of meditation found lengthening over just 3 weeks, in the retreat group (Conklin et al., 2018).

Importantly, not all leukocytes are "telomerically" equal. Subsets of lymphocytes from the same individual show different lengths of telomeres, such as shorter telomeres in CD8 T cells compared to B cells (Lin et al., 2010). Importantly, leukocyte composition is sensitive to acute stressors, and even a relatively brief (i.e., 5-min) activation of the sympathetic nervous system can elicit selective lymphocyte subtype mobilization and redistribution (e.g., resulting in apparent changes in NF- $\mathrm{kB}$ that actually represent selective mobilization of leukocytes with greater basal NF- $\kappa B$ activity in the absence of any true change in per-cell NF- $\kappa B$ activity; Richlin et al., 2004). This acute immune cell trafficking can lead to differences in cell subtypes present, and thus can result in different average measures of telomere length at that snapshot in time. This phenomenon of increased average telomere length in blood, termed "pseudo-lengthening" (Epel, 2012), could provide one plausible explanation for the overall trend toward telomere lengthening from baseline to post-intervention in our sample. A finger-prick can be stressful, particularly when performed by a stranger in a novel laboratory space. Specifically, the initial finger prick may have served as a novel acute stressor, eliciting leukocyte redistribution, to which the participant habituated by the second finger prick at the 4-week follow-up. However, we would 


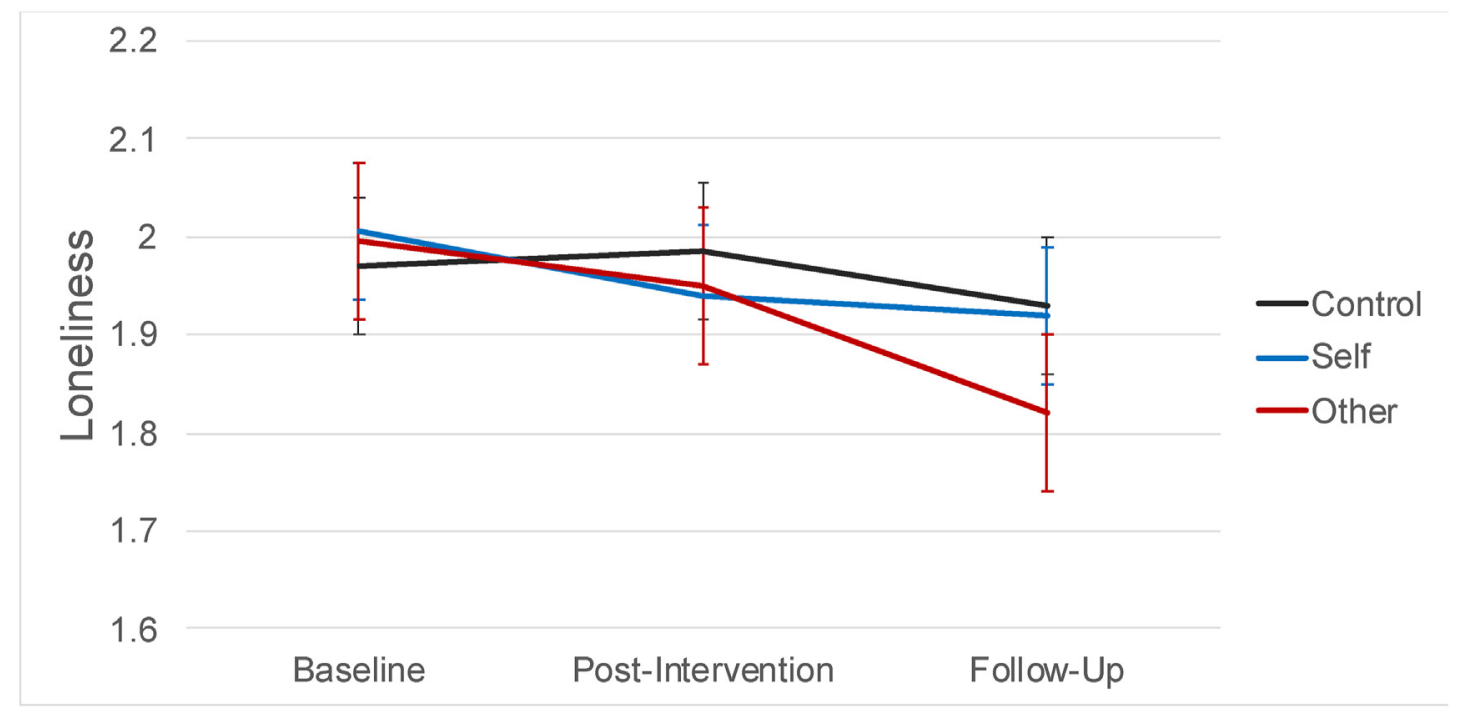

Fig. 3. Change in Loneliness by Condition. Note. Change in loneliness from baseline through the 2-week follow-up for each experimental condition.

expect this habituation effect to be similar across the full sample, and there are no reasons to expect it to differ across experimental groups (as observed in our secondary analyses). It is nevertheless possible that the kindness-to-others group may have had a muted stress and cell trafficking response, and this may in turn explain lack of a pseudo-lengthening effect of redistribution. This idea is speculative, but could be tested in future studies when cell types are measured at each time point (i.e., at the same time as venipuncture or finger pricks).

\subsection{Psychological outcomes}

Our pre-registered hypotheses regarding kindness to others and changes in well-being were also not supported. However, exploratory analyses revealed a pattern of results suggesting that engagement in either kindness activity led to reductions in loneliness across time. This finding supports our prediction that engaging in kindness to others may lead individuals to feel closer and more connected to others in their lives.

Additionally, we found that participants in the other-kindness group reported changes across time in loneliness, but only when the follow-up time period was included (i.e., via growth curve modeling). One explanation for this effect is that changes in loneliness may take longer than our 4-week intervention period to emerge. Additionally, given that growth modeling incorporates repeated measurements over time, this analysis may represent a more accurate assessment of change. The lonelinessalleviating potential of prosocial behavior is particularly timely, as social isolation is a recent public health concern and has been identified as a target for intervention efforts (e.g., Holt-Lunstad et al., 2017).

Our hypotheses regarding improvements in psychological variables were largely unsupported. One potential reason that we did not replicate the psychological flourishing finding reported by Nelson et al. (2016) is that, despite using the same intervention, our sample size was approximately half as large due to budgetary constraints for blood assays. Thus, we may have been underpowered to detect psychological effects. A post-hoc analysis suggests that in order to attain $80 \%$ power, we would have needed 1592 participants per experimental condition. Importantly, however, prior work using this prosocial behavior paradigm has found biological effects even in the absence of self-reported psychological effects (e.g., Nelson-Coffey et al., 2017). Furthermore, a recent study ( $N=$ 142) found significant differences in telomere length attrition between a loving-kindness meditation group and wait list control group (Le Nguyen et al., 2019).

To our knowledge, this study is the first pre-registered experiment to test the effect of a positive psychological intervention on change in telomere length across time. While there is now a growing body of intervention studies with telomere length, few of these were specifically designed for the outcome of telomere measurement, and none were preregistered.

\subsection{Limitations and future directions}

Our shortitudinal trial occurred over the course of just 4 weeks and employed a relatively low touch intervention. As most telomere intervention studies are highly intensive, multicomponent, and even sometimes residential, it is possible that our intervention was not potent enough (e.g., needed more acts than 3 times a week) or lengthy enough (e.g., needed to be longer than 4 weeks) to elicit the predicted changes in telomere length, and/or that our 1-month time lag was too brief to detect changes in telomere length. Additionally, we chose not to assess telomere length at the 2-week follow up, because we did not expect intervention effects to be evident over a brief, non-active follow-up period and due to the cost of the assays. However, it is possible that the effects of our intervention may have taken time to germinate, particularly in light of our loneliness finding. Thus, future work should strive to establish the optimal dosage for kindness interventions and the optimal time lag for measuring telomere length.

Our sample was largely healthy and in early-to-mid adulthood, and thus may not have had a lot of room for improvement. We may have observed stronger psychosocial and biological effects had we targeted a clinical and/or highly stressed sample. A meta-analysis found that the relationship between perceived stress and telomere length, although small, is marginally stronger in high stress and/or clinical samples compared to general samples (Mathur et al., 2016). Although traumatic distress is associated with shorter telomere length, particularly early in life (Li et al., 2017; Willis et al., 2018), no studies to our knowledge have demonstrated cross-sectional relationships between telomere length and measures of psychological well-being, such as positive affect (for exceptions of some studies on optimism, with mixed results, see Ikeda et al., 2014; Schutte et al., 2014). Thus, it is possible that enhancement of well-being in relatively healthy samples may not slow telomere attrition in the same way that alleviation of chronic stress might do so. Additionally, we did not assess depressive or anxiety disorders, which may have impacted baseline telomere length. However, there is little evidence to suggest that psychiatric history would impact the effect of our intervention on change in telomere length. Moreover, any such effects that might occur should be randomly distributed across study condition (given this study's randomized experimental design) and thus cannot account for the presence or 
absence of group differences in change over time. Finally, future studies could also measure telomere length with alternative methods, such as using buccal cells in addition to blood, given the inherent measurement error and fluctuation in blood cell types over time.

\section{Concluding words}

We conducted the first pre-registered positive psychological (i.e., prosocial behavior) intervention aimed at impacting telomere health. Our pre-registered hypotheses regarding psychological well-being and telomere length were not supported. Even participants who reported the biggest gains in well-being and related constructs from our intervention failed to show parallel shifts in telomere length. Further, collapsing across experimental conditions, neither single timepoint measures nor pre-post changes in psychological variables were significantly correlated with telomere health. Exploratory analyses, however, suggested that performing kindness may alleviate loneliness, thereby highlighting prosocial behavior as a potentially useful—brief, self-delivered, low-cost, and scalable-intervention for addressing a key public health concern.

\section{Financial disclosure}

The authors have no financial relationships relevant to this article to disclose.

\section{Funding}

This work was supported by a grant from Hopelab, Inc. The funders had no roles in study design and conduct of the study; collection, management, analysis, and interpretation of the data; preparation, review, or approval of the manuscript; or decision to submit the manuscript for publication.

\section{Declaration of competing interest}

None.

\section{Appendix A. Supplementary data}

Supplementary data to this article can be found online at https://do i.org/10.1016/j.bbih.2020.100187.

\section{References}

Aviv, A., Chen, W., Gardner, J.P., Kimura, M., Brimacombe, M., Cao, X., Srinivasan, S.R. Berenson, G.S., 2009. Leukocyte telomere dynamics: longitudinal findings among young adults in the Bogalusa Heart Study. Am. J. Epidemiol. 169, 323-329. https:// doi.org/10.1093/aje/kwn338.

Berglund, K., Reynolds, C.A., Ploner, A., Gerritsen, L., Hovatta, I., Pedersen, N.L., Hägg, S. 2016. Longitudinal decline of leukocyte telomere length in old age and the association with sex and genetic risk. Aging (Albany NY) 8, 1398-1407.

Biegler, K.A., Anderson, A.K., Wenzel, L.B., Osann, K., Nelson, E.L., 2012. Longitudinal change in telomere length and the chronic stress response in a randomized pilot biobehavioral clinical study: implications for cancer prevention. Canc. Prev. Res. 5, 1173-1182. https://doi.org/10.1158/1940-6207.CAPR-12-0008.

Blackburn, E.H., 2000. Telomere states and cell fates. Nature 408, 53-56.

Blackburn, E.H., Epel, E.S., Lin, J., 2015. Human telomere biology: a contributory and interactive factor in aging, disease risks, and protection. Science 350, 1193-1198. https://doi.org/10.1126/science.aab3389.

Bowling, N.A., Beehr, T.A., Swader, W.M., 2005. Giving and receiving social support at work: the roles of personality and reciprocity. J. Vocat. Behav. 67, 476-489. https:// doi.org/10.1016/j.jvb.2004.08.004.

Brown, S.L., Brown, R.M., 2015. Connecting prosocial behavior to improved physical health: contributions from the neurobiology of parenting. Neurosci. Biobehav. Rev. 55, 1-17. https://doi.org/10.1016/j.neubiorev.2015.04.004.

Carr, D.C., Kail, B.L., Matz-Costa, C., Shavit, Y.Z., 2018. Does becoming a volunteer attenuate loneliness among recently widowed older adults? J. Gerontol.: Ser. Bibliogr. 73, 501-510. https://doi.org/10.1093/geronb/gbx092.

Cawthon, R.M., 2002. Telomere measurement by quantitative PCR. Nucleic Acids Res. 30 e47. https://doi.org/10.1093/nar/30.10.e47 e47.

Codd, V., Nelson, C.P., Albrecht, E., Mangino, M., Deelen, J., Buxton, J.L., Hottenga, J.J., Fischer, K., Esko, T., Surakka, I., Broer, L., Nyholt, D.R., Leach, I.M., Salo, P., Hägg, S.,
Matthews, M.K., Palmen, J., Norata, G.D., O'Reilly, P.F., Samani, N.J., 2013. Identification of seven loci affecting mean telomere length and their association with disease. Nat. Genet. 45, 422. https://doi.org/10.1038/ng.2528.

Cohen, S., Kamarck, T., Mermelstein, R., 1983. A global measure of perceived stress. J. Health Soc. Behav. 24, 386-396. https://doi.org/10.2307/2136404.

Conklin, Q.A., King, B.G., Zanesco, A.P., Lin, J., Hamidi, A.B., Pokorny, J.J., Álvarez López, M.J., Cosín-Tomás, M., Huang, C., Kaliman, P., Epel, E.S., Saron, C.D., 2018. Insight meditation and telomere biology: the effects of intensive retreat and the moderating role of personality. Brain Behav. Immun. 70, 233-245. https://doi.org/ 10.1016/j.bbi.2018.03.003.

Diener, E., Emmons, R.A., 1984. The independence of positive and negative affect. J. Pers. Soc. Psychol. 47, 1105-1117. https://doi.org/10.1037/0022-3514.47.5.1105.

Diener, E., Emmons, R.A., Larson, R.J., Griffin, S., 1985. The satisfaction with life scale. J. Pers. Assess. 49, 71-75. https://doi.org/10.1207/s15327752jpa4901_13.

Dormann, C., Griffin, M.A., 2015. Optimal time lags in panel studies. Psychol. Methods 20, 489-505. https://doi.org/10.1037/met0000041.

Eisenberger, N.I., Cole, S.W., 2012. Social neuroscience and health: neurophysiological mechanisms linking social ties with physical health. Nat. Neurosci. 15, 669-674. https://doi.org/10.1038/nn.3086.

Epel, E., 2012. How "reversible" is telomeric aging? Canc. Prev. Res. 5, 1163-1168. https://doi.org/10.1158/1940-6207.CAPR-12-0370.

Farzaneh-Far, R., Lin, J., Epel, E., Lapham, K., Blackburn, E., Whooley, M.A., 2010. Telomere length trajectory and its determinants in persons with coronary artery disease: longitudinal findings from the Heart and Soul Study. PloS One 5. https:// doi.org/10.1371/journal.pone.0008612 e8612.

Holt-Lunstad, J., Robles, T.F., Sbarra, D.A., 2017. Advancing social connection as a public health priority in the United States. Am. Psychol. 72, 517. https://doi.org/10.1037/ amp.0000103.

Ikeda, A., Schwartz, J., Peters, J.L., Baccarelli, A.A., Hoxha, M., Dioni, L., Spiro III, A., Sparrow, D., Vokonas, P., Kubzansky, L.D., 2014. Pessimistic orientation in relation to telomere length in older men: the VA Normative Aging Study. Psychoneuroendocrinology 42, 68-76. https://doi.org/10.1016/ j.psyneuen.2014.01.001.

Jacobs, T.L., Epel, E.S., Blackburn, E.H., Wolkowitz, O.M., Bridwell, D.A., Zanesco, A.P., Aichele, S.R., Sahdra, B.K., MacLean, K.A., King, B.G., Shaver, P.R., Rosenberg, E.L., Ferrer, E., Wallace, B.A., Saron, C.D., 2011. Intensive meditation training, immune cell telomerase activity, and psychological mediators. Psychoneuroendocrinology 36 , 664-681. https://doi.org/10.1016/j.psyneuen.2010.09.010.

Jenkinson, C.E., Dickens, A.P., Jones, K., Thompson-Coon, J., Taylor, R.S., Rogers, M., Bambra, C.L., Lang, I., Richards, S.H., 2013. Is volunteering a public health intervention? A systematic review and meta-analysis of the health and survival of volunteers. BMC Publ. Health 13, 773. https://doi.org/10.1186/1471-2458-13-773.

Keyes, C.L.M., 2002. The mental health continuum: from languishing to flourishing in life. J. Health Soc. Behav. 43, 207-222. https://doi.org/10.2307/3090197.

Le Nguyen, K.D., Lin, J., Algoe, S.B., Brantley, M.M., Kim, S.L., Brantley, J., Salzberg, S., Fredrickson, B.L., 2019. Loving-kindness meditation slows biological aging in novices: evidence from a 12-week randomized controlled trial.

Psychoneuroendocrinology 108, 20-27. https://doi.org/10.1016/ j.psyneuen.2019.05.020.

Li, X., Wang, J., Zhou, J., Huang, P., Li, J., 2017. The association between post-traumatic stress disorder and shorter telomere length: A systematic review and meta-analysis. J. Affect. Disord. 218, 322-326.

Lin, J., Epel, E., Cheon, J., Kroenke, C., Sinclair, E., Bigos, M., Wolkowitz, O., Mellon, S., Blackburn, E., 2010. Analyses and comparisons of telomerase activity and telomere length in human $\mathrm{T}$ and $\mathrm{B}$ cells: insights for epidemiology of telomere maintenance. J. Immunol. Methods 352, 71-80. https://doi.org/10.1016/j.jim.2009.09.012.

Mathur, M.B., Epel, E., Kind, S., Desai, M., Parks, C.G., Sandler, D.P., Khazeni, N., 2016. Perceived stress and telomere length: a systematic review, meta-analysis, and methodologic considerations for advancing the field. Brain Behav. Immun. 54, 158-169. https://doi.org/10.1016/j.bbi.2016.02.002.

Moieni, M., Irwin, M.R., Haltom, K.E.B., Jevtic, I., Meyer, M.L., Breen, E.C., Cole, S.W., Eisenberger, N.I., 2018. Exploring the role of gratitude and support-giving on inflammatory outcomes. Emotion 19, 939-949. https://doi.org/10.1037/ emo0000472.

Moieni, M., Irwin, M.R., Seeman, T.E., Robles, T.F., Lieberman, M.D., Breen, E.C., Okimoto, S., Lengacher, C., Arevalo, J.M.G., Cole, S.W., Eisenberger, N.I., 2020. Feeling needed: effects of a randomized generativity intervention on well-being and inflammation in older women. Brain Behav. Immun. 84, 97-105. https://doi.org/ 10.1016/j.bbi.2019.11.014.

Nelson-Coffey, S.K., Fritz, M.M., Lyubomirsky, S., Cole, S.W., 2017. Kindness in the blood: the gene regulatory impact of prosocial behavior. Psychoneuroendocrinology 81, 8-13. https://doi.org/10.1016/j.psyneuen.2017.03.025.

Nelson, S.K., Layous, K., Cole, S., Lyubomirsky, S., 2016. Do unto others or treat yourself?: the effects of prosocial and self-focused behavior on psychological flourishing. Emotion 16, 850-861. https://doi.org/10.1037/emo0000178.

Ornish, D., Lin, J., Chan, J.M., Epel, E., Kemp, C., Weidner, G., Marlin, R., Frenda, S.J., Magbanua, M.J.M., Daubenmier, J., Estay, I., Hills, N.K., Chainani-Wu, N., Carroll, P.R., Blackburn, E.H., 2013. Effect of comprehensive lifestyle changes on telomerase activity and telomere length in men with biopsy-proven low-risk prostate cancer: 5-year follow-up of a descriptive pilot study. Lancet Oncol. 14, 1112-1120. https://doi.org/10.1016/S1470-2045(13)70366-8.

Puhlmann, L.M., Valk, S.L., Engert, V., Bernhardt, B.C., Lin, J., Epel, E.S., Vrtička, P., Singer, T., 2019. Association of short-term change in leukocyte telomere length with cortical thickness and outcomes of mental training among healthy adults: a randomized clinical trial. JAMA Network Open 2. https://doi.org/10.1001/ jamanetworkopen.2019.9687 e199687-e199687. 
Richlin, V.A., Arevalo, J.M., Zack, J.A., Cole, S.W., 2004. Stress-induced enhancement of NF-KB DNA-binding in the peripheral blood leukocyte pool: effects of lymphocyte redistribution. Brain Behav. Immun. 18, 231-237. https://doi.org/10.1016/ j.bbi.2003.08.001.

Russell, D., Peplau, L.A., Cutrona, C.E., 1980. The revised UCLA Loneliness Scale: Concurrent and discriminant validity evidence. J. Pers. Soc. Psychol. 39, 472-480.

Schreier, H.M., Schonert-Reichl, K.A., Chen, E., 2013. Effect of volunteering on risk factors for cardiovascular disease in adolescents: a randomized controlled trial. JAMA Pediatrics 167, 327-332. https://doi.org/10.1001/jamapediatrics.2013.1100.

Schutte, N.S., Malouff, J.M., 2014. A meta-analytic review of the effects of mindfulness meditation on telomerase activity. Psychoneuroendocrinology 42, 45-48. https:// doi.org/10.1016/j.psyneuen.2013.12.017.
Seeman, T., Merkin, S.S., Goldwater, D., Cole, S.W., 2020. Intergenerational mentoring, eudaimonic well-being and gene regulation in older adults: a pilot study. Psychoneuroendocrinology 111. https://doi.org/10.1016/j.psyneuen.2019.104468, 104468 .

Sheldon, K.M., Hilpert, J.C., 2012. The balanced measure of psychological needs (BMPN) scale: an alternative domain general measure of need satisfaction. Motiv. Emot. 36, 439-451. https://doi.org/10.1007/s11031-012-9279-4.

Willis, M., Reid, S.N., Calvo, E., Staudinger, U.M., Factor-Litvak, P., 2018. A scoping systematic review of social stressors and various measures of telomere length across the life course. Ageing Res. Rev. 47, 89-104. https://doi.org/10.1016/ j.arr.2018.07.006. 